\title{
Opposing states of subtidal habitat across temperate Australia: consistency and predictability in kelp canopy-benthic associations
}

\author{
Meegan J. Fowler-Walker, Sean D. Connell* \\ Department of Environmental Biology, University of Adelaide, Adelaide, South Australia 5005, Australia
}

\begin{abstract}
We tested the view that few generalizations are possible about the structure of subtidal algae assemblages and that the situation worsens or does not change as more sites are examined. We quantified the percentage cover of 4 morphological groups of benthic algae (encrusting and articulated coralline algae, and foliose and turfing algae) under canopies of kelp Ecklonia radiata and in areas without kelp (macroalgae $>4 \mathrm{~cm}$ high). This was repeated over 4 spatial scales ranging from quadrats (separated by 10s of m), sites (separated by $\mathrm{km}$ ), locations (separated by $100 \mathrm{~s}$ of $\mathrm{km}$ ) to regions (separated by 1000s of $\mathrm{km}$ ) across the southern coastline of Australia: Western Australia (WA), Southern Australia (SA) and Eastern Australia (EA). The key result was that while comparison among sites revealed substantial and often inconsistent variation in abundance of benthic algae between habitats (kelp vs open), clear patterns emerged when locations and regions were compared. In EA, where grazers are effective in maintaining extensive areas of encrusting corallines, patterns of algal cover between habitats (kelp vs open) were generally reversed to WA and SA, where grazers are substantially less effective. These results indicate a large distinction in the ecology of these regions (WA $=\mathrm{SA} \neq \mathrm{EA}$ ) and how lack of understanding of this pattern at the regional scale tends to suggest overwhelming variation when single studies are compared among regions. These differences also highlight that comparisons of studies done at small scales, even if done at several sites in a locality, provide a difficult basis to understand the generality of pattern in algal assemblage structure due to large variation at this scale. While we acknowledge that these broad patterns were not possible to validate at the scale of sites, it was possible to increase the scale of observation to encompass broader patterns that might be organized around a relatively simple set of ecological predictions.
\end{abstract}

KEY WORDS: Biogeographic $\cdot$ Generality $\cdot$ Region $\cdot$ Scale $\cdot$ Variation

Resale or republication not permitted without written consent of the publisher

\section{INTRODUCTION}

Ecology may have numerous laws in the form of widespread, repeatable patterns in nature. However, to discover such general patterns research efforts need to be increased to encompass studies of patterns over biogeographic regions (Lawton 1996). In the past 25 to $30 \mathrm{yr}$, however, coastal marine ecology has focused heavily on manipulative experiments over spatial scales of 10s to 100s of m (Underwood et al. 2000). It is

${ }^{*}$ Corresponding author. E-mail: sean.connell@adelaide.edu.au argued that at these smaller scales, substantial variation obscures generalizations and ecologists need to increase their scales of observation to encompass broader patterns that might be organized around a few relatively simple underlying rules (Lawton 1999).

Past attempts at generalities of pattern over biogeographic scales have based their arguments on the relative numbers of papers demonstrating particular patterns of organization (Foster 1990) and this has led to unsatisfying disagreements (cf. Foster 1991, Paine 1991). Others have extrapolated the results of studies done at smaller scales across biogeographic regions, which has often led to poorly understood generalities 
(Hurlbert 1984). Ultimately, the most complete generalities will be obtained when observations span the range of regions of interest (Foster 1990) and incorporate several smaller spatial scales of observation (Underwood \& Champan 1996, Beck 1997). This search for generalities is fundamentally based upon understanding ecological patterns across local to global scales (Underwood \& Petraitis 1993, Gaston \& Blackburn 1999).

One encouraging set of observations is that ecological assemblages vary in predictable ways with differences in the structure of their habitat. This predictability often occurs to the extent that pieces of habitat are identified as appropriate units of study. On subtidal rocky reefs, the presence of forests of macroalgae have such strong spatial relationships with the benthic algae growing underneath them (Kennelly 1987, Edwards 1998, Melville \& Connell 2001) that these groups of species are often referred to as canopy and understorey species. Despite the apparent consistency of this pattern, there remains substantial doubt over the extent to which spatial generalities are possible for algal assemblages. Where direct attempts have been made to quantify spatial variability over regional scales $(<1000 \mathrm{~km})$, it has been concluded that as more sites are examined, fewer generalizations concerning structure were appropriate (Choat \& Schiel 1982, Schiel 1990).

In Australia, some of the most extensive and widespread kelp forests are formed by the common kelp Ecklonia radiata. Numerous studies describe the distribution and abundance of subtidal algae at either a few locations (e.g. Shepherd \& Womersley 1970, 1981, May \& Larkum 1981, Kennelly 1987) or as a suite of habitats in Eastern Australia (Andrew \& Underwood 1989, Underwood et al. 1991, Kennelly \& Underwood 1992), but these studies have been done at relatively fine spatial scales compared to their extensive distribution along the southern coastline of Australia.

This paper was motivated by strong experimental effects of Ecklonia radiata on the structure of benthic algae at one locality in South Australia (Melville \& Connell 2001) which seemed incompatible with knowledge of these assemblages elsewhere in Australia (e.g. Daume et al. 1999). A frustrating aspect of these differences is the way they are used to highlight 'inconsistent' effects, which only reinforces the idea that few generalizations are possible despite the reality that such assessments are premature when no coherent description of these assemblages are available to allow such judgements.

A decade ago, reviews of the ecology of marine algae (references in Chapman \& Underwood 1990) emphasized the need to determine the applicability of simple, generalized models over vast biogeographic scales. In this paper, we test the hypotheses that there are con- sistent broad-scale patterns in assemblages of algae when simple, broad taxonomic groups or functional groups (sensu Steneck \& Dethier 1994) are compared between kelp forests (monospecific stands of Ecklonia radiata) and open habitats (devoid of macroalgae). We also test the hypothesis that patterns are discernable within locations and across the regions Western Australia (WA), South Australia (SA) and Eastern Australia (EA) which are not apparent at smaller spatial scales (sites).

\section{MATERIALS AND METHODS}

Sites and sampling methods. Assemblages of subtidal algae and invertebrate grazers were quantified between October 2000 and January 2001 across the southern coastline of Australia: WA, SA and EA (Fig. 1; $3400 \mathrm{~km}$ linear distance, $>5100 \mathrm{~km}$ coastal distance). Regions were separated by 1000s of $\mathrm{km}$ and chosen so that they fell between the latitudes $33^{\circ} 59^{\prime} \mathrm{N}$ and $35^{\circ} 51^{\prime} \mathrm{S}$. This restriction was intended to reduce variation caused by well-known latitudinal gradients $(\mathrm{N}-\mathrm{S}$ gradients). Within each region, we selected 3 locations (separated by $100 \mathrm{~s}$ of $\mathrm{km}$ ) and 4 sites (separated by $\mathrm{km}$ ) within each location. Scales of separation were based on linear distance. All sites were chosen so that they were of similar exposure, connected to the mainland and at the same depth (3 to $10 \mathrm{~m}$ ).

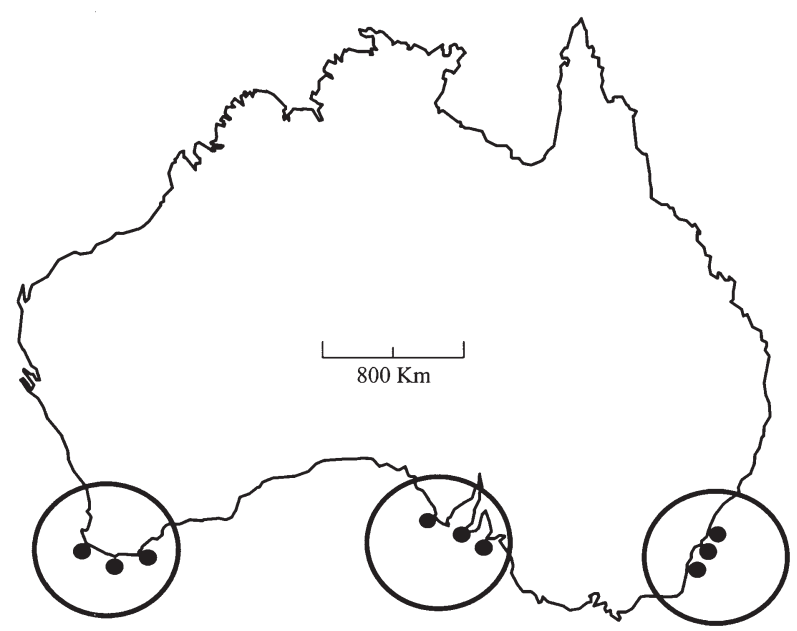

Fig. 1. The regions and locations of sampling which were chosen to minimize latitudinal variation ( $33^{\circ} 9^{\prime} \mathrm{N}$ to $\left.35^{\circ} 51^{\prime} \mathrm{S}\right)$. Moving left to right, these locations were: Cape Leeuwin, Albany and Esperance (Western Australia); Eyre Peninsula, Yorke Peninsula and Fleurieau Peninsula (South Australia); and Batemans Bay, Jervis Bay and Sydney (Eastern Australia). Within each location, the percentage covers of algae and densities of grazing invertebrates were sampled at 4 replicate sites (separated by 1 to $10 \mathrm{~km}$ ) in each of 6 replicate quadrats 
Within each site, the percentage cover of benthic organisms was sampled within 2 types of habitat: monospecific stands of Ecklonia radiata (hereafter termed 'kelp habitats') and habitats devoid of all macrophytic algae (hereafter termed 'open habitats'), where macrophytic algae are defined as any algae greater than $4 \mathrm{~cm}$ in height. This height restriction was used to exclude other types of macroalgae that form canopies analogous to E. radiata (namely Cystosiraceae). Generally, both habitats were patchily distributed within the same depth (3 to $10 \mathrm{~m})$. Quadrats $\left(1 \mathrm{~m}^{2}\right.$; $\mathrm{n}=6$ ) were haphazardly placed among different patches separated by a minimum distance of $10 \mathrm{~m}$ and were positioned $>1 \mathrm{~m}$ from the edge of a patch. Densities of E. radiata were estimated per $1 \mathrm{~m}^{2}$ quadrat.

Benthic assemblages within each $1 \mathrm{~m}^{2}$ quadrat were quantified using three $10 \times 10 \mathrm{~cm}$ quadrats (comprising 25 points) by the point intersection method (Meese \& Tomich 1992) to obtain an estimate of percentage cover. Benthic algae were categorized into 4 functional groups according to their morphology (Steneck \& Dethier 1994): crustose coralline algae (which grow prostrate to the substratum), the erect growth forms of articulated algae, foliose algae and turfing algae (which include filamentous turfs and those combined with sediment). Taxa were counted if they were directly attached to rock or crustose coralline algae (recognizing that crustose coralline algae occurred on almost all rock surfaces and acted as substratum for most other groups of algae). Crustose coralline algae per se were counted when not overgrown by other algae. In EA one $10 \times 10 \mathrm{~cm}$ was sampled per $1 \mathrm{~m}^{2}$ quadrat. Within each $1 \mathrm{~m}^{2}$ quadrat, the abundance of the 4 most numerically dominant herbivores were sampled; sea urchins (Centrostephanus rodgersii, Heliocidaris erythrogramma), turbinid gastropods (Australium tentiforme, Turbo torquata), limpets (Cellana tramoserica, Patelloida mufria, Patelloida aticostata Patella chapman) and abalone (Haliotis laevigata).

Analytical methods. Percentage cover was combined among the three $10 \times 10 \mathrm{~cm}$ quadrats sampled in each $1 \mathrm{~m}^{2}$ quadrat in WA and SA to provide a balanced design with an equal number of replicates at all spatial scales. Multivariate analyses were done on 4th-roottransformed Bray-Curtis dissimilarities among replicate $1 \mathrm{~m}^{2}$ quadrats. A non-parametric multi-dimensional scaling (MDS) plotted the centriod (average) of replicate sites within each habitat to represent the dissimilarity among locations $(n=3)$ within each region. A 2-factor non-parametric analysis of variance (NPMANOVA; Anderson 2001) tested the relative and interactive effects of habitat (kelp vs open) and region (WA vs SA vs EA) on assemblage structure (percentage cover) of benthic organisms. Multiple pairwise- comparisons (see Anderson 2001) tested for differences in benthic assemblage structure between habitats at each region. Analysis treated 'Habitat' and 'Region' as fixed, and locations and sites were treated as replicates ( $\mathrm{n}=72$ ) because NP-MANOVA can only be applied to a 2-factor design. Analysis of variance tested spatial differences among the 4 most abundant algal functional groups (comprising 95\% of percentage cover). Four-factor ANOVA treated 'Habitat' and 'Region' as fixed and orthogonal to one another, and 'Location' and 'Site' as random factors nested within the hierarchy of spatial scales. Pair-wise comparisons (SNKtests) were used to test for differences between open and kelp habitats for each spatial scale (e.g. the interaction between Habitat and Region or Site). Prior to analysis, data were tested for homogeneity of variances using Cochran's C-Test (Underwood 1981). Heterogeneous data were either $\ln (x+1)$ or $\ln (x+0.05)$ transformed. If these transformations did not remove heteroscedasticity, the raw data were used for the analysis with a more conservative $\alpha$-value, so that 0.05 significance was judged at 0.01 and 0.01 judged at 0.001 .

\section{RESULTS}

Assemblages of benthic algae differed between kelp and open habitats in all regions (Fig. 2, Table 1; Habitat $\times$ Region interaction). Pair-wise comparisons determined EA to have the smallest magnitude of difference

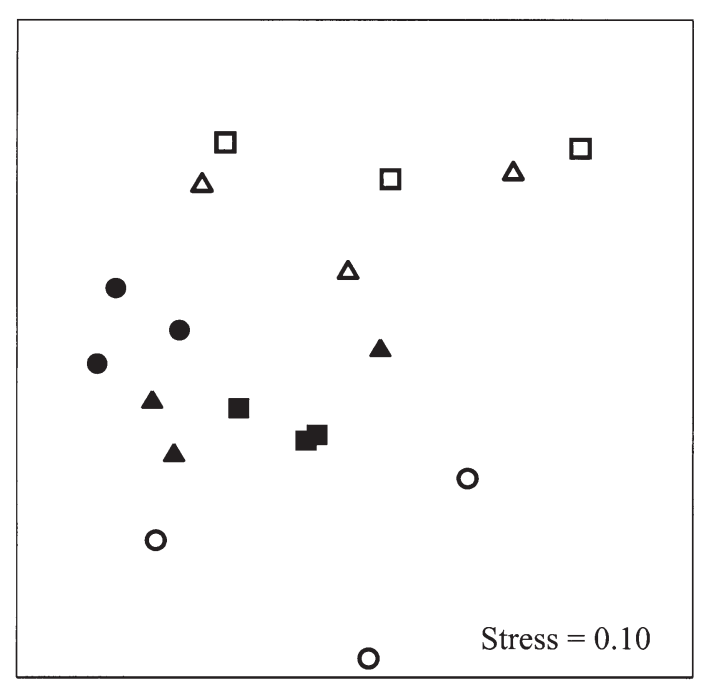

Fig. 2. Non-parametric multidimensional scaling analyses showing associations of benthic algae assemblages between kelp habitats (filled symbols) and open habitats (unfilled symbols) within each region, Western, South and Eastern Australia, $\mathbf{\square}, \boldsymbol{\Delta}$ and $\boldsymbol{\bullet}$, respectively 
Table 1. Results of (a) 2-factor NP-MANOVA and (b) pairwise comparisons of terms in significant Habitat $\times$ Region interaction. WA $=$ Western Australia, $\mathrm{SA}=$ South Australia, $\mathrm{EA}=$ Eastern Australia

\begin{tabular}{|c|c|c|c|c|}
\hline (a) Treatment & df & MS & $F$ & $\mathrm{p}$ \\
\hline Habitat & 1 & 95131.00 & 133.02 & $* * *$ \\
\hline Region & 2 & 45884.80 & 133.02 & $* * *$ \\
\hline Habitat $\times$ Region & 2 & 84797.97 & 118.57 & *** \\
\hline Residual & 426 & 715.15 & & \\
\hline Total & 431 & & & \\
\hline \multicolumn{3}{|c|}{ (b) Pair-wise comparisons } & $t$ & $\mathrm{p}$ \\
\hline \multirow{3}{*}{\multicolumn{2}{|c|}{ Habitat (Kelp vs Open) }} & WA & 13.4 & *** \\
\hline & & SA & 12.3 & $* * *$ \\
\hline & & EA & 7.8 & *** \\
\hline \multirow{3}{*}{\multicolumn{2}{|c|}{ Region (Kelp) }} & WA vs SA & 3.2 & $* * *$ \\
\hline & & WA vs EA & 5.8 & *** \\
\hline & & SA vs EA & 4.5 & *** \\
\hline \multirow{3}{*}{\multicolumn{2}{|c|}{ Region (Open) }} & WA vs SA & 1.4 & ns \\
\hline & & WA vs EA & 15.1 & *** \\
\hline & & SA vs EA & 17.5 & *** \\
\hline \multicolumn{5}{|c|}{ Not significant (ns): $\mathrm{p}>0.05,{ }^{* * *} \mathrm{p}<0.001$} \\
\hline
\end{tabular}
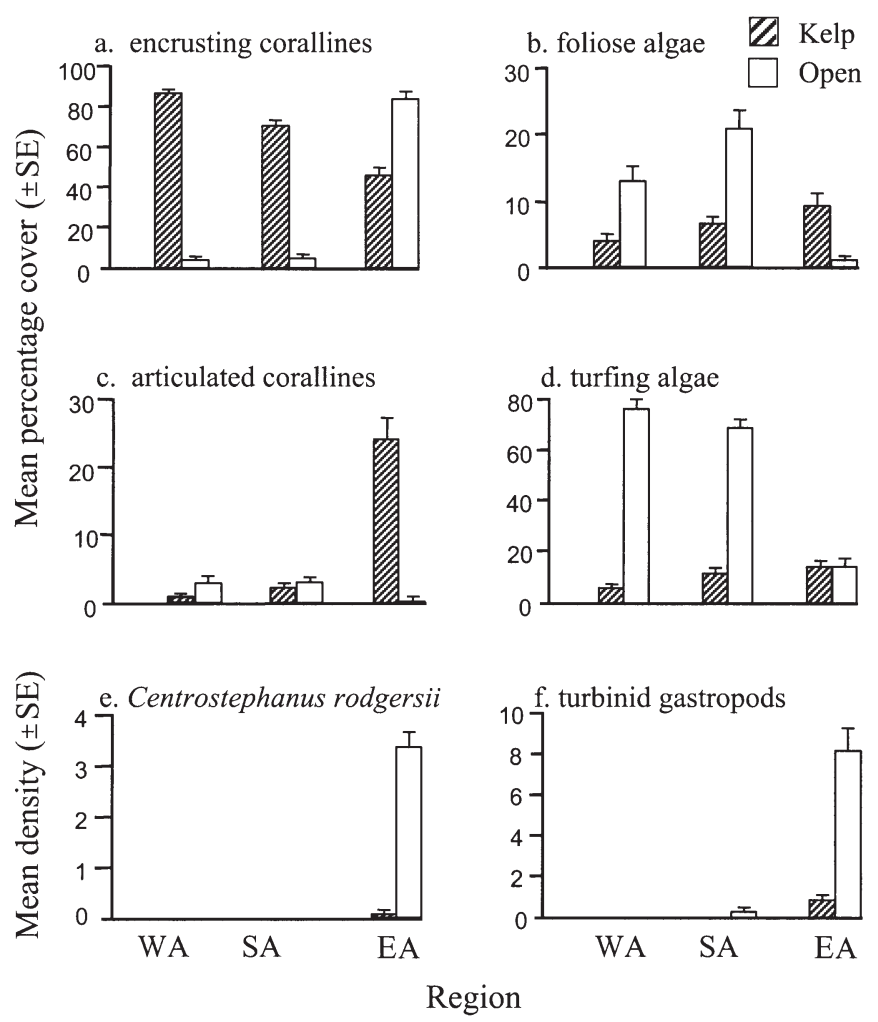

Fig. 3. Percentage cover $( \pm S E ; n=6)$ of morphological groups of algae ( $\mathrm{a}$ to $\mathrm{d}$ ) and density of grazers $\left( \pm \mathrm{SE}_{;} \mathrm{n}=6\right)$ between kelp and open habitats within each region $(\mathrm{WA}=$ Western Australia, SA = South Australia, EA = Eastern Australia) in structure of assemblages between kelp forests and open habitats $(t=7.8, \mathrm{p}<0.001)$ compared to WA $(t=13.4, \mathrm{p}<0.001)$ and SA $(t=12.3, \mathrm{p}<0.001)$. The structure of benthic assemblages in kelp forests differed among regions (Table 1) with the greatest differences occurring between WA and EA $(t=5.8$, $\mathrm{p}<0.001)$, and the least between SA and EA $(t=4.5$, $\mathrm{p}<0.001)$ and WA and SA $(t=3.2, \mathrm{p}<0.001)$. Comparison of open habitats indicated that algal assemblages differed significantly between WA and EA $(t=15.1$, $\mathrm{p}<0.001)$ and SA and EA $(t=17.5, \mathrm{p}<0.001)$, but not between WA and SA $(t=1.4, \mathrm{p}>0.05)$.

Analysis of variance revealed consistent differences between habitats (kelp vs open) within each region for the most abundant groups of algae (i.e. algae that contributed to $>95 \%$ of the percentage cover). This difference between habitats, however, was not consistent across regions in that patterns in EA were often reversed in WA and SA (Fig. 3a-d, Table 2a-d: Habitat $\times$ Region interaction). The percentage cover of encrusting corallines was greater in kelp forests than open habitats in WA and SA, but the opposite occurred in EA (Fig. 3a and Table 2a; SNK-tests). The percentage covers of foliose and articulated algae were greater in kelp than open habitats in EA and did not differ between habitats in WA and SA (Fig. 3b,c and Table 2b,c; SNK-tests). The cover of turfing algae was sparse in EA and did not differ between habitats, but WA and SA had extensive covers of turfing algae which were greater outside kelp forests (Fig. 3d and Table 2d; SNK-tests). At intermediate scales (among locations), there was no significant variation in the magnitude or direction of differences in percentage covers between habitats from location to location within each region (Habitat $\times$ Location [Region]), except for articulated algae (Table $2 \mathrm{a}-\mathrm{d}$ ). Hence, figures present estimates of percentage cover and variance $( \pm \mathrm{SE}$ ) for each region given these consistencies (Fig. 3).

In general, there was substantial site to site variation in the covers of algae between kelp and open habitats (Habitat $\times$ Site [Location (Region)]; Table 2a-d). While the rank-order of these differences generally matched those at regional scales for encrusting corallines (Table 3), there was considerable inconsistency for the remaining groups (Table 3). For example, evidence that the covers of foliose algae were greater inside than outside kelp forests of EA (as observed at regional scales, above) was poor and even appears baseless when sites are compared (Table 3).

Urchins were at least 35 times more abundant in open habitats in EA (mean \pm SE, $3.361 \pm 0.285)$ than in SA $(0.097 \pm 0.069)$ and WA (no urchins). This pattern is consistent with the total density of all remaining grazers in open habitats, which were at least 24 times more abundant in EA (5.519 \pm 0.620$)$ than in SA 
$(0.231 \pm 0.069)$ and WA (no grazers observed). A significant Habitat $\times$ Region interaction term was detected for the 2 numerically dominant groups of invertebrate grazers (sea urchins and turbinid gastropods), with large abundances being unique to EA (Fig. 3e,f and Table 2e,f). With the exception of Heliocidaris erythrogramma at 1 site in Elliston (SA), sea urchins Centrostephanus rodgersii were only observed in EA. In EA the densities of $C$. rodgersii were substantially greater in open than kelp habitats (Fig. 3e). The same pattern was observed for the combined densities of turbinid gastropods (Australium tentiforme and Turbo torquata) (Fig. 3f and Table 2f; SNK-tests). Only 2 other types of grazers were observed: limpets
(Cellana tramoserica, Patelloida mufria, Patelloida aticostata and Patella chapman) in open habitats of EA $\left(8.29 \pm 1.294 \mathrm{~m}^{-2}, \mathrm{n}=6\right)$ and abalone Haliotis laevigata in a single site off Elliston, $\mathrm{SA}$ (open: $4 \pm 0.683 \mathrm{~m}^{-2}$, $\mathrm{n}=6$; kelp: $0.667 \pm 0.667 \mathrm{~m}^{-2}, \mathrm{n}=6$ ).

\section{DISCUSSION}

These results demonstrate that despite enormous spatial variability in covers of benthic algae associated with open and kelp habitats at smaller spatial scales (i.e. sites separated by $\mathrm{km}$ ), there were strong consistencies of pattern within regions (localities separated

Table 2. ANOVA testing differences in the percentage cover of morphological groups of algae and the density of grazers among habitats, regions, locations and sites

\begin{tabular}{|c|c|c|c|c|c|c|c|}
\hline Source & $\mathrm{df}$ & MS & $F$ & $\mathrm{p}$ & MS & $F$ & $\mathrm{p}$ \\
\hline & \multicolumn{3}{|c|}{ (a) Encrusting corallines } & & \multicolumn{2}{|c|}{ (b) Foliose algae } & \\
\hline Habitat & 1 & 147852.00 & 29.21 & $* * *$ & 6.18 & 1.10 & ns \\
\hline Region & 2 & 28660.46 & 8.35 & ** & 53.96 & 32.90 & $* * *$ \\
\hline Location (Region) & 6 & 3431.45 & 2.67 & ns & 1.64 & 0.47 & ns \\
\hline Site (Region [Location]) & 27 & 1285.75 & 5.87 & $* * *$ & 3.46 & 3.21 & *** \\
\hline Habitat $\times$ Region & 2 & 154661.57 & 30.55 & $* * *$ & 42.04 & 7.48 & * \\
\hline Habitat $\times$ Location (Region) & 6 & 5061.92 & 2.81 & ns & 5.62 & 1.96 & $\mathrm{~ns}$ \\
\hline Habitat $\times$ Site (Region [Location]) & 27 & 1804.35 & 8.24 & $* * *$ & 2.87 & 2.66 & *** \\
\hline \multirow[t]{2}{*}{ Residual } & 360 & 256.36 & & & 1.08 & & \\
\hline & \multicolumn{3}{|c|}{ (c) Articulated corallines } & & \multicolumn{2}{|c|}{ (d) Turfing algae } & \\
\hline Habitat & 1 & 201.29 & 8.33 & * & 198489.81 & 68.11 & $* * *$ \\
\hline Region & 2 & 23.03 & 0.29 & ns & 34150.52 & 8.58 & ** \\
\hline Location (Region) & 6 & 80.17 & 7.88 & $* * *$ & 3981.37 & 2.98 & ns \\
\hline Site (Region [Location]) & 27 & 10.17 & 3.98 & $* * *$ & 1334.40 & 5.21 & *** \\
\hline Habitat $\times$ Region & 2 & 229.97 & 9.52 & $*$ & 50952.26 & 17.48 & ** \\
\hline Habitat $\times$ Locacation (Region) & 6 & 24.15 & 3.48 & $* * *$ & 2914.30 & 1.63 & ns \\
\hline Habitat $\times$ Site (Region [Location]) & 27 & 6.93 & 2.71 & ${ }^{* * *}$ & 1788.13 & 6.97 & $* * *$ \\
\hline \multirow[t]{2}{*}{ Residual } & 360 & 2.56 & & & 256.36 & & \\
\hline & \multicolumn{3}{|c|}{ (e) Urchins } & & \multicolumn{2}{|c|}{ (f) Turbinid gastropods } & \\
\hline Habitat & 1 & 137.81 & 46.33 & $* * *$ & 25.7 & 29.74 & *** \\
\hline Region & 2 & 137.34 & 46.90 & $* * *$ & 43.65 & 7.93 & * \\
\hline Location (Region) & 6 & 2.93 & 1.25 & ns & 5.5 & 3.08 & ns \\
\hline Site (Region [Location]) & 27 & 2.35 & 2.73 & $* * *$ & 1.79 & 17.88 & *** \\
\hline Habitat $\times$ Region & 2 & 126.29 & 42.46 & $* * *$ & 19.82 & 22.94 & *** \\
\hline Habitat $\times$ Location (Region) & 6 & 2.97 & 1.46 & ns & 0.86 & 1.04 & ns \\
\hline Habitat $\times$ Site (Region [Location]) & 27 & 2.04 & 2.37 & $* * *$ & 0.83 & 8.31 & *** \\
\hline \multirow[t]{2}{*}{ Residual } & 360 & 0.86 & & & 0.1 & & \\
\hline & \multicolumn{2}{|c|}{ (g) Limpets } & & & \multicolumn{2}{|l|}{ (h) Abalone } & \\
\hline Habitat & 1 & 30.16 & 16.07 & ** & 0.93 & 1.00 & ns \\
\hline Region & 2 & 30.16 & 16.07 & $* *$ & 1.81 & 1.00 & ns \\
\hline Location (Region) & 6 & 1.88 & 2.17 & ns & 1.81 & 1.00 & $\mathrm{~ns}$ \\
\hline Site (Region [Location]) & 27 & 0.87 & 9.93 & $* * *$ & 1.81 & 23.90 & $* * *$ \\
\hline Habitat $\times$ Region & 2 & 30.16 & 16.07 & $* *$ & 0.93 & 1.00 & ns \\
\hline Habitat $\times$ Location (Region) & 6 & 1.88 & 2.17 & ns & 0.93 & 1.00 & ns \\
\hline Habitat $\times$ Site (Region [Location]) & 27 & 0.87 & 9.93 & $* * *$ & 0.93 & 12.20 & *** \\
\hline Residual & 360 & 0.09 & & & 0.07 & & \\
\hline
\end{tabular}


Table 3. Number of sites per region ( $\mathrm{n}=12$ per region) with patterns of benthic cover that were inconsistent with those detected at the regional scale. Inconsistency was determined by matching pair-wise SNK-tests of kelp vs open habitats for Sites (Habitat $\times$ Sites [Region (Location)]) with Regions (Habitat $\times$ Region)

\begin{tabular}{|lccc|}
\hline Benthic algae & WA & SA & EA \\
\hline Encrusting corallines & Kelp > Open & Kelp $>$ Open & Kelp $<$ Open \\
Foliose algae & 0 & 0 & 1 \\
& Kelp = Open & Kelp $=$ Open & Kelp $>$ Open \\
Articulated corallines & 5 & 4 & 7 \\
& Kelp = Open & Kelp $=$ Open & Kelp $>$ Open \\
Turfing algae & 3 & 3 & 2 \\
& Kelp $<$ Open & Kelp $<$ Open & Kelp = Open \\
Total inconsistencies (out of 48) & 9 & 1 & 6 \\
& 9 & 8 & 16 \\
\hline
\end{tabular}

other areas of Australia's temperate coastline. Most of Australia's ecological studies of subtidal algae are based on Eastern Australia (New South Wales) and emphasize particular patterns and views, which have subsequently become 'knowledge', making alternate findings from other regions appear troublesome (authors' pers. obs.).

The reported severity of inconsistency in algal structure has also had a persuasive influence on our view of subtidal algal assemblages, with some authors appearing surprised about consistencies of canopy-understorey associations across studies done in vastly different parts of the world (e.g.

by 100 s of $\mathrm{km}$ ) and across regions (WA and SA separated by $1000 \mathrm{~s}$ of $\mathrm{km}$ ). At small scales (i.e. among sites), the percentage covers of algae varied to the extent that it appeared that many patterns were inconsistent and few generalizations were appropriate. Small-scale, local heterogeneity in habitat and abundance of taxa is well documented in marine systems, including Australian intertidal (Underwood \& Chapman 1989) and subtidal rocky reefs (Kennelly 1987). However, recent work on intertidal reefs demonstrates that such variability declines rapidly with increases in spatial scale of sampling (Underwood \& Chapman 1996).

Patterns of algal assemblages within regions (among localities) were remarkably consistent and inconsistencies among regions appear predictable given known aspects of the ecology of each region. In Eastern Australia, where macrograzers (primarily, Centrostephanus rodgersii) maintain extensive covers of encrusting coralline algae free of epiphytes and macroalgae (Fletcher 1987, Andrew \& Underwood 1993), the covers of this encrusting alga are greater outside than inside kelp forests. In WA and SA, however, where grazers are largely ineffective and are sparsely distributed (Jones \& Andrew 1990), encrusting coralline algae are over grown by extensive covers of epiphytes outside but not inside kelp forests. Hence the pattern is reversed. Indeed such reversal of patterns between regions (WA $=\mathrm{SA} \neq \mathrm{EA}$ ) occurs for all 4 functional groups (encrusting coralline, articulated coralline, turf and foliose algae).

These differences highlight what appear to be very real differences in ecology between regions (WA = $\mathrm{SA} \neq \mathrm{EA}$ ) and how comparison of single, small-scale studies among these regions can be mistakenly used to suggest overwhelming variation at all scales. Our results also warn that insights from studies done in EA need to be carefully evaluated before being applied to
Edwards 1998). We note that regional differences in the structure of benthic assemblages in open versus kelp habitats $(\mathrm{WA}=\mathrm{SA} \neq \mathrm{EA}$ ) support Chapman \& Johnson's alternative states model for which grazing has a substantial influence (Chapman \& Johnson 1990) over broad scales (Table 3 ). The extensive covers of fleshy, erect algae outside kelp forests in WA and SA appears to be a response to the lack of grazers able to maintain encrusting corallines free of epiphytic algae (review: Jones \& Andrew 1990) compared to EA, where grazers maintain extensive 'barrens' of encrusting corallines (Andrew 1993). Some of the most effective grazers in SA, i.e. grazing molluscs, can maintain encrusting corallines free of epiphytic algae for up to 3 mo (Shepherd \& Turner 1985), but recent experiments show that these effects do not persist much beyond this period (S. Connell unpubl. data exceeding $2.5 \mathrm{yr})$. Indeed, these recent manipulations demonstrate that the presence/absence of kelp has the greatest effect on assemblage structure independent of the presence/absence of grazers.

Although algal patterns of abundance appeared predictable across large scales (and much less predictable across smaller scales), we do not advocate that grazing or a single process generates these broad patterns. What we are at pains to emphasize is that such consistencies may be predictable with knowledge of the presence/absence of kelp and particular types of grazers despite a lack of knowledge on the underlying mechanisms (e.g. Peters 1991). To us, such insights are encouraging because they suggest that attempts to increase the scale of observation around a relatively few simple rules may not only be possible (Lawton 1999), but may also provide new insights.

To understand the cause of consistencies of pattern over biogeographic scales, the processes acting at these scales, such as oceanography and biohistory, need to be considered (Dayton \& Tegner 1984, Ricklefs 
1987, Levin 1992, Ricklefs \& Schluter 1993). The influence of regional and historical factors becomes apparent when the greatest variation among regions occurs among the most distant regions (Ricklefs \& Schluter 1993). Such was the case for assemblages associated with kelp forests, for which the most difference was observed between the most geographically separated regions (i.e. WA vs EA). This disparity indicates that local assemblages may not be isolated within the narrow context of local processes (Dayton \& Tegner 1984) and may reflect regional or even historical circumstances (Ricklefs \& Schluter 1993).

The use of broad taxonomic groups (e.g. functional groups) may not be useful for all ecological tests (e.g. Phillips et al. 1997, Benedetti-Cecchi 2000), but they show considerable promise and receive increasing use in marine ecology (Warwick \& Clarke 1991, Chapman 1998). Our results illustrate the value of this approach in addition to that of taxonomic identity. While most species have restricted geographical ranges, their 'group' is sufficiently widespread to enable comparisons among regions. Hence, broad groupings enable us to increase our scale of observation (using easily identifiable taxa) to test broad-scale patterns and underlying ecological concepts.

In conclusion, it has long been revealed that the scale at which we make ecological observations may have profound consequences for the patterns and processes that we identify. However, we are not always mindful of the constraints imposed by our scale of observation and tend to either attempt broad generalizations (which can be premature) or to become so mesmerized by proximate details that we fail to discern broader patterns and predictive understanding (Wiens et al. 1986). For those inspired by similarities (repeatable patterns), then the widely observable patterns are encouraging. Such patterns may not only provide opportunities to uncover general laws in ecology (Lawton 1999), but may also provide hope that ecology can achieve more than the discovery of new details (dissimilarity in patterns) and the common criticism of 'stamp collecting' in ecological research (Underwood et al. 2000). Theories of broad-scale patterns may seem holistic (Peters 1991) but the critical element is not so much whether they account for all the variance of a noisy world, but whether they have predictive power which provides a basis of new discovery.

Acknowledgements. S.D.C. would like to thank A. Underwood, G. Chapman and the late R. Peters for insightful discussions on broad-scale studies and predictive frameworks in ecology. Over $5000 \mathrm{~km}$ of exposed coastline could not have been painstakingly sampled whilst lacking major incident without the capable diving and boating expertise of L. Ashwins, B. Gillanders, A. Irving and S. Drabsh. Special thanks to the fishing villages of the Southern Ocean, particularly the town of Elliston, which provided a local crew to navigate our 18 yr old boat through stormy passages and evade great white sharks. This study was supported by Australian Research Council grants to S.D.C.

\section{LITERATURE CITED}

Anderson MJ (2001) A new method for non-parametric multivariate analysis of variance in ecology. Aust Ecol 26:32-46

Andrew NL (1993) Spatial heterogeneity, sea urchin grazing, and habitat structure on reefs in temperate Australia. Ecology 74:292-302

Andrew NL, Underwood AJ (1989) Patterns of abundance of the sea urchin Centrostephanus rodgersii (Agassiv) on the central coast of New South Wales, Australia. J Exp Mar Biol Ecol 131:61-80

Andrew NL, Underwood AJ (1993) Density-dependent foraging in the sea urchin Centrostephanus rodgersii on shallow subtidal reefs in News South Wales, Australia. Mar Ecol Prog Ser 99:89-98

Beck MW (1997) Inference and generality in ecology: current problems and an experimental solution. Oikos 78:265-273

Benedetti-Cecchi L (2000) Priority effects, taxonomic resolution, and prediction of variable patterns of colonisation of algae in littoral rock pools. Oecologia 123:265-274

Chapman ARO, Johnson CR (1990) Disturbance and organization of macroalgal assemblages in the Northwest Atlantic. Hydrobiologia 192:77-121

Chapman ARO, Underwood AJ (eds) (1990) Determinants of structure in intertidal and subtidal macroalgal assemblages. Hydrobiologia (Spec Issue) 192:1

Chapman M (1998) Relationships between spatial patterns of benthic assemblages in a mangrove forest using different levels of taxonomic resolution. Mar Ecol Prog Ser 162: $71-78$

Choat JH, Schiel DR (1982) Patterns of distribution and abundance of large brown algae and invertebrate herbivores in subtidal regions of northern New Zealand. J Exp Mar Biol Ecol 60:129-162

Daume S, Brand-Gardner S, Woelkerling WJ (1999) Community structure of nongeniculate coralline red algae (Corallinales, Rhodophyta) in three boulder habitats in southern Australia. Phycologia 38:138-148

Dayton PK, Tegner MJ (1984) The importance of scale in community ecology: a kelp forest example with terrestrial analogs. In: Price PW, Slobodchikoff CN, Gaud WS (eds) A new ecology: novel approaches to interactive systems. John Wiley \& Sons, Chichester, p 457-481

Edwards MS (1998) Effects of long-term kelp canopy exclusion on the abundance of the annual alga Desmarestia ligulata (Light F). J Exp Mar Biol Ecol 228:309-326

Fletcher WJ (1987) Interactions among subtidal Australian sea urchins, gastropods and algae: effects of experimental removals. Ecol Monogr 57:89-109

Foster MS (1990) Organization of macroalgal assemblages in the Northeast Pacific: the assumption of homogeneity and the illusion of generality. Hydrobiologia 192:21-33

Foster MS (1991) Rammed by the Exxon Valdez: a reply to Paine. Oikos 62:93-96

Gaston KG, Blackburn TM (1999) A critique for macroecology. Oikos 84:353-368

Hurlbert SH (1984) Pseudoreplication and the design of ecological field experiments. Ecol Monogr 54:187-211

Jones GP, Andrew NL (1990) Herbivory and patch dynamics on rocky reefs in temperate Australasia: the roles of fish and sea urchins. Aust J Ecol 15:505-520 
Kennelly SJ (1987) Physical disturbances in an Australian kelp community. II. Effects on understorey species due to differences in kelp cover. Mar Ecol Prog Ser 40:155-165

Kennelly SJ, Underwood AJ (1992) Fluctuations in the distributions and abundances of species in sublittoral kelp forests in New South Wales. Aust J Ecol 17:367-382

Lawton JH (1996) Patterns in ecology. Oikos 75:145-147

Lawton JH (1999) Are there general laws in ecology? Oikos 84:177-192

Levin SA (1992) The problem of pattern and scale in ecology. Ecology 73:1943-1967

May V, Larkum AWD (1981) A subtidal transect in Jervis Bay, EA. Aust J Ecol 6:429-457

Meese RJ, Tomich PA (1992) Dots on the rocks: a comparison of percent cover estimation methods. J Exp Mar Biol Ecol 165:59-73

Melville AJ, Connell SD (2001) Experimental effects of kelp canopies on subtidal coralline algae. Aust Ecol 26:102-108

Paine RT (1991) Between Scylla and Charybdis: Do some kinds of criticism merit a response? Oikos 62:90-92

Peters RH (1991) A critique for ecology. Cambridge University Press, New York

Phillips JC, Kendrick GA, Lavery PS (1997) A test of a functional group approach to detecting shifts in macroalgal communities along a disturbance gradient. Mar Ecol Prog Ser 153:125-138

Ricklefs RE (1987) Community diversity: relative roles of local and regional processes. Science 235:167-171

Ricklefs RE, Schluter D (1993) Species diversity in ecological communities. University of Chicago Press, Chicago

Schiel DR (1990) Macroalgal assemblages in New Zealand: structure, interactions and demography. Hydrobiologia 192:59-76

Shepherd SA, Turner JA (1985) Studies on southern Australian abalone (genus Haliotis). VI. Habitat preference, abundance and predators of juveniles. J Exp Mar Biol Ecol 93:285-298

Shepherd SA, Womersley HBS (1970) The sublittoral ecology

Editorial responsibility: Otto Kinne (Editor),

Oldendorf/Luhe, Germany of West Island, South Australia. 1. Environmental features and algal ecology. Trans R Soc S Aust 94:105-137

Shepherd SA, Womersley HBS (1981) The algal and seagrass ecology of Waterloo Bay, South Australia. Aquat Bot 11: 305-371

Steneck RS, Dethier MN (1994) A functional group approach to the structure of algal-dominated communities. Oikos 69:476-498

Underwood AJ (1981) Techniques of analysis of variance in experimental marine biology and ecology. Oceanogr Mar Biol Annu Rev 19:513-605

Underwood AJ, Chapman MG (1989) Experimental analyses of the influences of topographic of the substratum on movements and density of an intertidal snail, Littorina unifasciata. J Exp Mar Biol Ecol 134:175-196

Underwood AJ, Chapman MG (1996) Subtidal assemblages on rocky reefs at a cliff-face sewage outfall (North Head, Sydney, Australia): What happened when the outfall was turned off? Mar Pollut Bull 33:293-302

Underwood AJ, Petraitis PS (1993) Structure of intertidal assemblages in different locations: How can local processes be compared? In: Ricklefs R, Schluter D (eds) Species diversity in ecological communities. University of Chicago Press, Chicago, p 38-51

Underwood AJ, Kingsford MJ, Andrew NL (1991) Patterns in shallow subtidal marine assemblages along the coast of New South Wales. Aust J Ecol 6:231-249

Underwood AJ, Chapman MG, Connell SD (2000) Observations in ecology: You can't make progress on processes without understanding the patterns. J Exp Mar Biol Ecol 250:97-115

Warwick RM, Clarke KR (1991) The comparison of some methods for analysing changes in benthic community structure. J Mar Biol Assoc UK 71:225-244

Wiens JA, Addicott JF, Case TJ, Diamond J (1986) Overview: the importance of spatial and temporal scale in ecological investigations. In: Diamond J, Case TJ (eds) Community ecology. Harper and Row, New York, p 145-153

Submitted: September 27, 2001; Accepted: April 30, 2002 Proofs received from author(s): August 12, 2002 